\title{
A Study on the Interdisciplinary Teaching Process of the Information Technology Applications on Cultural and Creative Product Design
}

\author{
Lu Li-Shu and Wu Pei-Fen
}

\begin{abstract}
In recent years, the trend of global education has been chiefly directed onto interdisciplinary talent cultivation, as well as encouraging teachers and students to enter the community field. The relationship between university education and the local community are being strengthened in order to drive more social innovation. The lifestyle in the rural areas are undergoing gradual changes and evolving, and there is strong hope to bring the vitality to the old-aged rural life where community withered. Therefore, this study takes the technical principles of the IT sensing application and the guidance of the interdisciplinary teaching, and carries out the design of the commodity development of rural culture. The overall teaching and research process is based on the view of the researcher as the educator, and through the participatory observation method and action research method to analyzed and introspected.

The practical design outcome is the "Huben Five-sense Image Poetry Collection". The development process is mainly guided by the teaching modules of designing and IT, and the cooperative learning. In this way, micro technology is applied to the design, and the image poetry collection is produced, developed and implemented accordingly. The whole process has gone through field and domain dialogues, teaching interaction, case analysis, cooperative communication, field assessment and calibration, and finally the proposal is submitted. Analytical result on teaching process of interdisciplinary collaboration design in this study aims to serve as reference for future interdisciplinary instruction or related research.
\end{abstract}

Index Terms - Information technology, rural community, cultural and creative products, interdisciplinary collaboration.

\section{INTRODUCTION}

With the evolution of modern life and digital science and technology, as well as the cultural and creative industries, the promotion and marketing of "unique features of township" is becoming more and more prominent. In recent years the global agricultural and rural life forms are gradually changing (Council of Agriculture, Executive Yuan, 2014) [1]. The various appearances of the rural life circle have attracted great attention; in the meantime, the global education is trending towards cultivating the interdisciplinaryd talents and

Manuscript received April 29, 2018; revised July 28, 2018.

$\mathrm{Lu} \mathrm{Li}-\mathrm{Shu}$ is with the Department and Graduate School of Digital Media Design, National Yunlin University of Science and Technology, Douliou, Yunlin City, Taiwan (e-mail: luls@gemail.yuntech.edu.tw).

Pei-Fen $\mathrm{Wu}$ is with the Department of Information Management and Master Program in Digital Content Technology and Management, National Chunghua University of Education, Chunghua, Taiwan (e-mail pfwu@cc.ncue.edu.tw). encouraging the teachers and students to enter the community field so as to strengthen the relationship between the university education and the community education, so as to inspire more social innovation (Ministry of Education, 2018) [2]. Therefore, it highlights the importance of the development trend of interdisciplinary talent cultivation and innovation curriculum model. Guided by that view point Module units planning and instruction of the curriculum will be based on interdisciplinary thinking model in order to diversely allow students to generally recognize concept of interdisciplinary collaboration and feasibility of innovative development.

According to The Ten Faces of Innovation of Tom Kelley and Jonathan Littman (2005), 3 categories and 10 kinds of characters were introduced. [3], Likewise, Kang (2017) integrated the concept and developed the core competence of T-type talent cultivation: experiential observation, including anthropologists and experiential architects; reflective feedback, including hurdle runners and storytellers; interdisciplinary collaboration, including cross-pollinators and partners; innovative design, including directors and stage designers; application technology, including experimenters and nurses. [4] Based on above, activation of rural villages and construction of characteristics can be based on practical education planning in universities. Thus, the emphasis of curriculum content refers to rural village promotion, activation of rural communities, rural village reconstruction, community activation, reconstruction of remote villages, activation of smart village communities, etc. By planning of interdisciplinary and cross-school curriculum collaboration, students with different backgrounds experience and explore living fields of rural villages by team work to probe into rural people's life style, analyze environmental characteristics of fields and conduct interdisciplinary collaboration design and practice by information and communication technology to propose design of cultural and creative products of rural villages with information and communication characteristics.

Hence, this study aims to focus on rural fields as base of instructional practice and introduce students of different professional backgrounds in rural fields to practice interdisciplinary teams and cooperation. Through brainstorming of teams, they reconstruct rural villages and establish the characteristics. By observation and record of instructional process, it aims to explore the phenomenon in interdisciplinary design instruction and interaction between teachers, students and fields to serve as reference for the following interdisciplinary design instruction. The course implementation framework is shown in Fig. 1. 


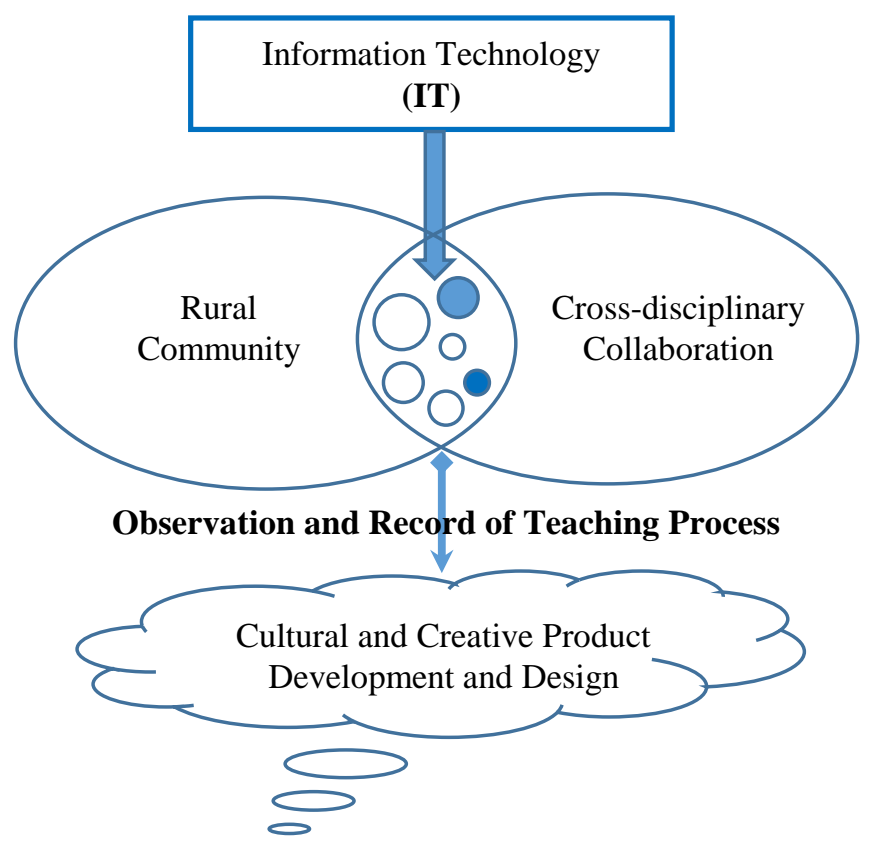

Fig. 1. The course implementation framework.

\section{RESEARCH DESIGN OF TEACHING}

This study mainly analyzes the teaching process of cross-disciplinary courses through action research and participatory observation methods. The overall research process can be divided into three stages, as follows:

\section{A. Curriculum Planning}

The teaching goal of the overall curriculum is based on human sensory perception experience, soundscape triangle theory proposed by R. Murray Schafer [5], [6], the Canadian composer and visual image construction of landscape in cities and countryside, and by introduction of technology innovation imported in design projects and intends to allow students to exchange with each other and design digital value added work with cultural thinking and playfulness. Operation of the curriculum is based on design thinking and double diamond design process model [7]. The process is divided into four stages: Discover, Define, Develop, and Deliver. In this curriculum, upon the theoretical model, it will implement interdisciplinary collaboration design of professional design and information technology courses. The course content is focus on meaning transformation of sound and images in the fields. The goals are professional design development and competence cultivation of Develop-Deliver of digital sound recording and sound software operation. It concerns about importance of exploration and thinking of overall environmental soundscape and finally it results in output of physical products. Instructional model refers to different units. The planning is based on characteristics of learners of different backgrounds (information and communication technology and design).

\section{B. Sensor Applied to Cultural and Creative Design}

Development of information technology makes progress with time and it not only changes human beings' lives, but also influences feasibility and innovative development of design instruction. In modern society, electronic sensors are everywhere. They exist in production, research \& development, test and all kinds of occasions associated with lives (Tan, 2014). [8].

This study explores electronic sensor device and technology in information technology and presents cultural features of rural villages by e-books, such as e-illustration books or digital video poetry collection, etc. For the concern of users' interaction and ease of use of devices, this study adopts sensor components including Light Sensor, vibration senor module, music playing module, as shown in Fig. 2.

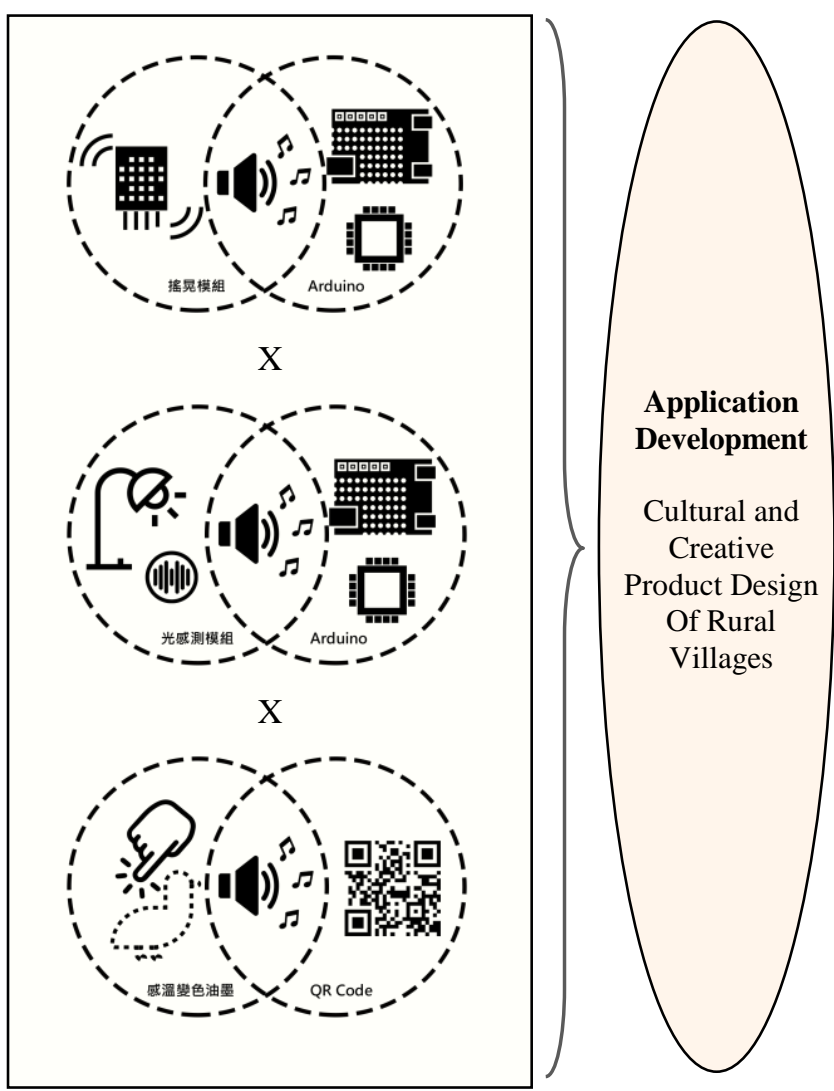

Fig. 2. Sensing technology imported in design concepts.

\section{Case Study - Huban Eco-Village}

On November 28, 2008, Taiwan government announced Huben village as "important habitat of wild animal Indian Pitta in Huben of Yunlin". They successfully protected their habitat and drew the attention from the world and government. They succeeded in preventing the digging of sandstone. Indian Pitta defended Huben village and Huben village conserved the free habitat for Indian Pitta and the place became internationally well-known environmental village (Chiu, 2010: Lee, 2016) [9], [10]. Residents of Huben village are mostly farmers. Since natural terrain and climate of Huben village are favorable to planting of crops, in four seasons, Huben produces abundantly bamboo shoots, oranges, pomelos, pineapples, etc. It is located in southeast of Linnei Township, Yunlin County and the altitudes are 100 300 meters. It is a hill and in the past, it was called Hushanliao, a small village in low mountain with mountains and rivers in the neighborhood. Stream of Dapu river is the core of the village and it constantly produces rich human and natural resources.

Therefore, upon local unique culture, space and industry, it promotes features of different villages in order to enhance 
competitiveness of rural tourism in Taiwan. It is one of the important issues in modern time. However, at present, there are abundant resources in Huben community without integrated development. It relies on planning and design of related topic. Therefore, this study treats Huben community of Low Mountain in Linnei Township, Yunlin County of Taiwan as the field (see Fig. 3).

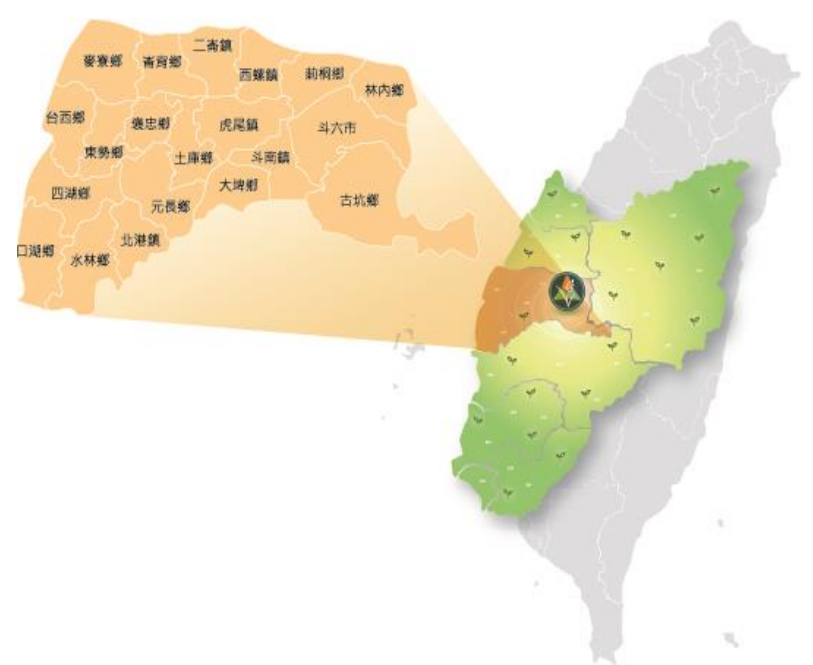

Fig. 3. The geographic location of the study case.

\section{INTERDISCIPLINARY TEACHING PROCESS DESCRIPTION}

According to the "White Paper on Human Resource Development of Ministry of Education" in 2013, key competence of human resources in the following decade is global mobility, employment competence, innovation, interdisciplinary competence, information competence and citizenship( Ministry of Education, 2013) [11]. In addition, according to Cheng's (2016) "Reimaging University Education: The Shifting Learning Ecosystems in Stanford 2025", the said researcher mentioned that Axis Flip learning ecology system of four systems mainly responds to requirement of modern competence-based learning and focuses on students' interdisciplinary technique and competence [12]. Johnson \& Johnson (1987) argued that collaborative learning means to not only sit closer, but also discuss, help and share with each other. It is instructional strategy and method to enhance students' learning outcome, learning transfer and cultivate their critical thinking capability [13].

Therefore, the curriculum development of this study aims to cultivate students' interdisciplinary and integrated thinking competence and analyze the cultivation process. First, through lectures, it presents theories related to soundscape and visual image in order to construct the learning base of the field with elaboration of related cases. Subsequently, by industry experts' collaborative instruction, through cultural and visual images, it integrates speeches of professional experts to teach students to establish concept of field image transformation and formation in order to strengthen practical competence of fields. Finally, by heterogeneous group collaboration, it practices project cooperation in order to solve problems observed in the fields and the members' questions. Furthermore, by module exchange, teachers can introduce module borrowing in the courses and complement the competence training through arranging modules of different fields and properties in order to fulfil interdisciplinary instruction. Instructional process is shown in Fig. 4 and the explanation is presented as follows:

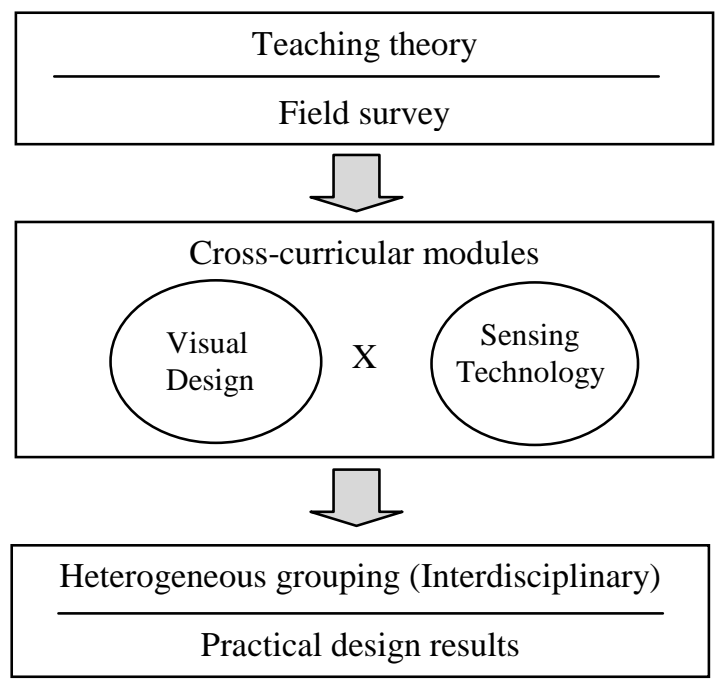

Fig. 4. Teaching planning and process.

\section{A. Definition of Rural Issues}

Through the interviews with local industry partners, this study found there are not many tourists in Huban Community, generally tourist would take form as holiday mountain climbing, or seasonal bird-watching visitors. Huban Community now has a lot of cultural creativity related products, for example, there are many kinds products of Pitta nympha for ecological conservation, but most of them tend to be designs with a single visual sense, for example fig. 5 . Therefore, the eco-cooperatives in this community want to make new ideas and plans for innovation. It hopes to focus on the promotion of ecological and environmental education, and the application of technology, so that visitors can gain a deeper understanding of the ecology there, so that there shall be integration and continuity for the previous cultural creativity products. The field issues are listed and shown in Table I:

\section{B. Design and Development Process}

It is based on sound and image research courses modules and implemented by thinking of service design, from 1D and 2D problem discovery and definition, 3D design ideas to finally 4D field practice. By participating in the project, students experience interdisciplinary recreation and tourism and application of information technology. Through five-sense experience photographic journals and application of micro-technology, they produce intellectual, perceptual and warm video stories by oranges of rural industry and the species, Indian Pitta. Thus, the audiences can specifically perceive life, production and ecology of Huben village. Application of information sensor technology includes jiggle modules, photoresistor sensor module, music playing module, Arduino related program writing, as shown in Fig. 6.

\section{Design Results and Display}

Huban Community's feeling towards its visitors are humane and full of warmth. Being warm, it generally gives people the 
feeling of being considerate and the feeling of warm temperature. But sometimes one must gain more in-depth understanding so that to feel its real temperature. The temperature is somewhat like the feeling and connection between people. This plan will add in the five-sense experience, so the visitors will not only gain a visual experience, but also obtain the experience of listening, sniffing, tasting and tactile, so that visitors can experience the real temperature of Huben more concretely and have a deeper memory. Prototype conceptual design figure is as shown in Fig. 7.

TABLE I: THE FIELD PROBLEMS AND REQUIREMENTS Field problems and requirements

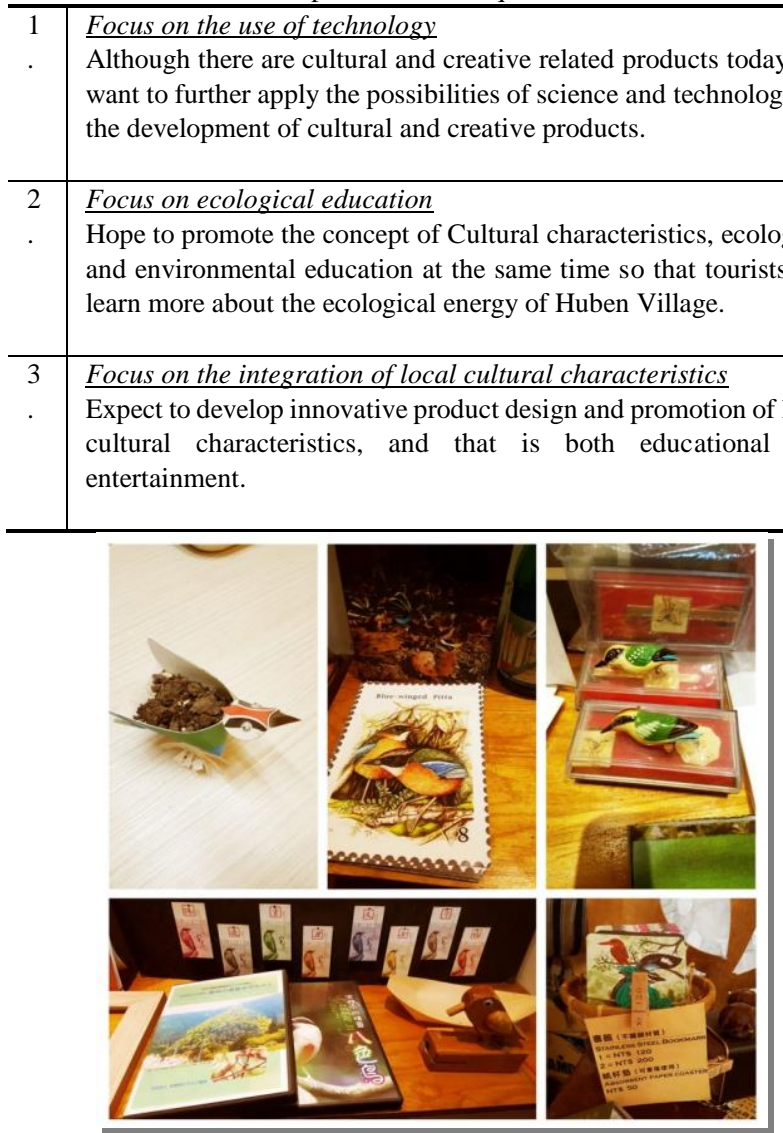

Fig. 5. Existing Pitta nympha's application products.
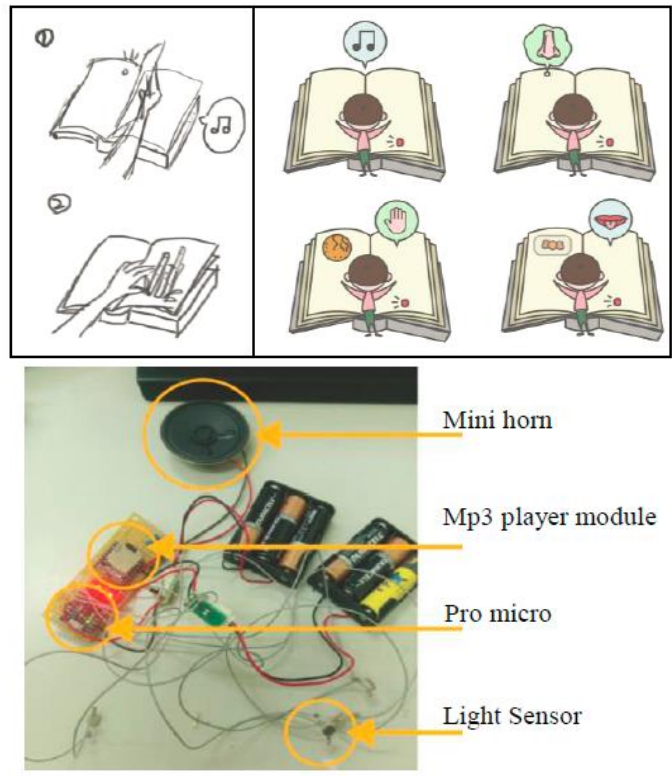

Fig. 6. Design and development process.

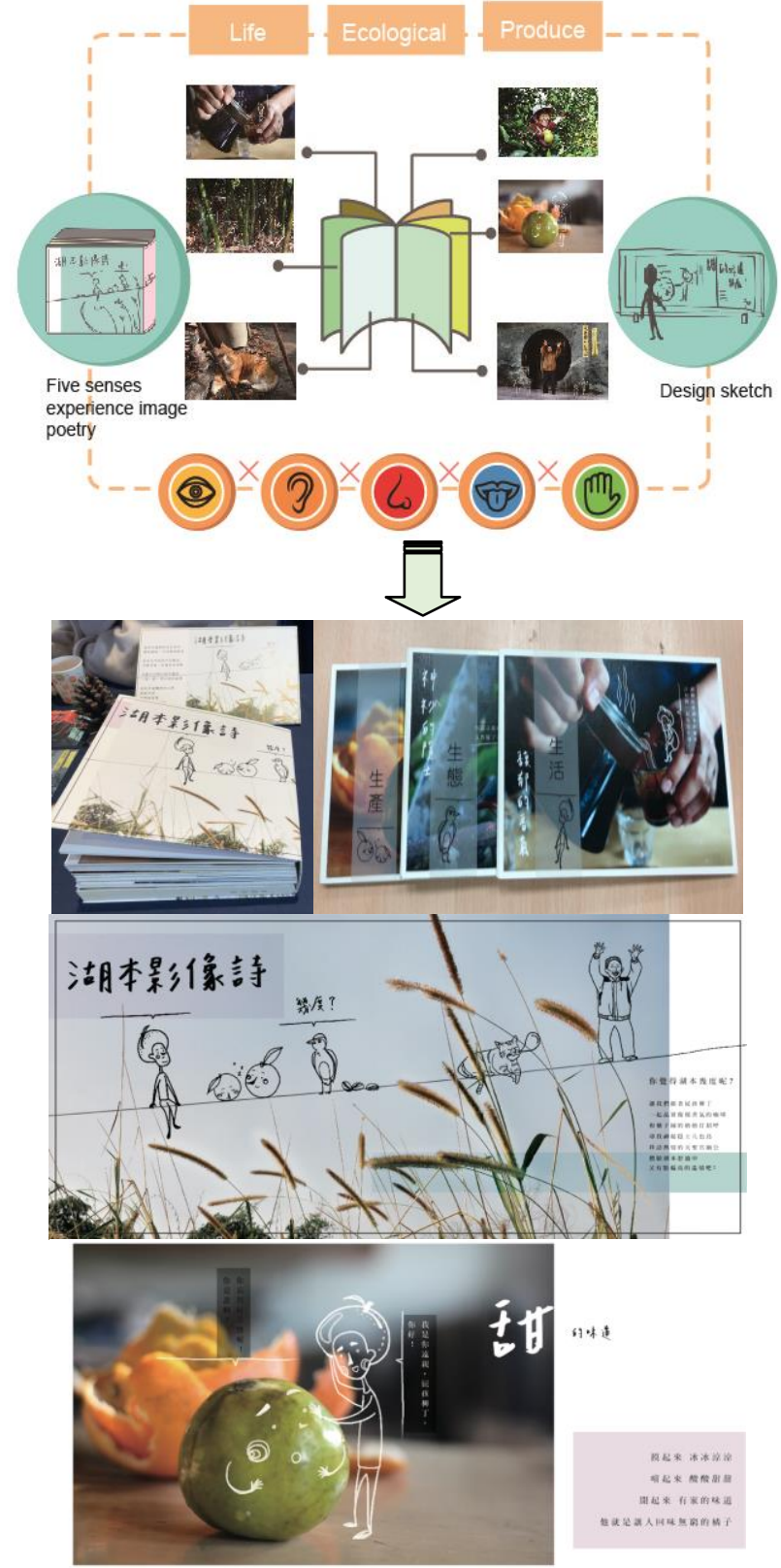

Fig. 7. Five sense experience and sensing technology application design works.

\section{CONCLUSION AND SUGGESTION}

In this curriculum, by cooperation between academic circle and industry of rural field, students explore the problems, experience and observe in Huben village of Linnei Township in Yunlin, and propose innovative ideas and solutions regarding current problems and demand of future development of field partners.

The overall teaching and research process is based on the view of the researcher as the educator, and through the participatory observation method and action research method to analyzed and introspected. In terms of overall instructional research and observation, this study argues that interdisciplinary instruction process is the evolution of integrated design and thinking. Thus, it combines instructional planning and design thinking process and proposes six phases of interdisciplinary collaboration design which are modified as six stages of interdisciplinary collaboration design, including field dialogue, instructional 
interaction, case analysis, cooperation and communication, field assessment and modification and finally the proposal of outcomes, as shown in Fig. 8.

Analytical result of instructional process of this study aims to serve as reference for future interdisciplinary instruction or related research topics.

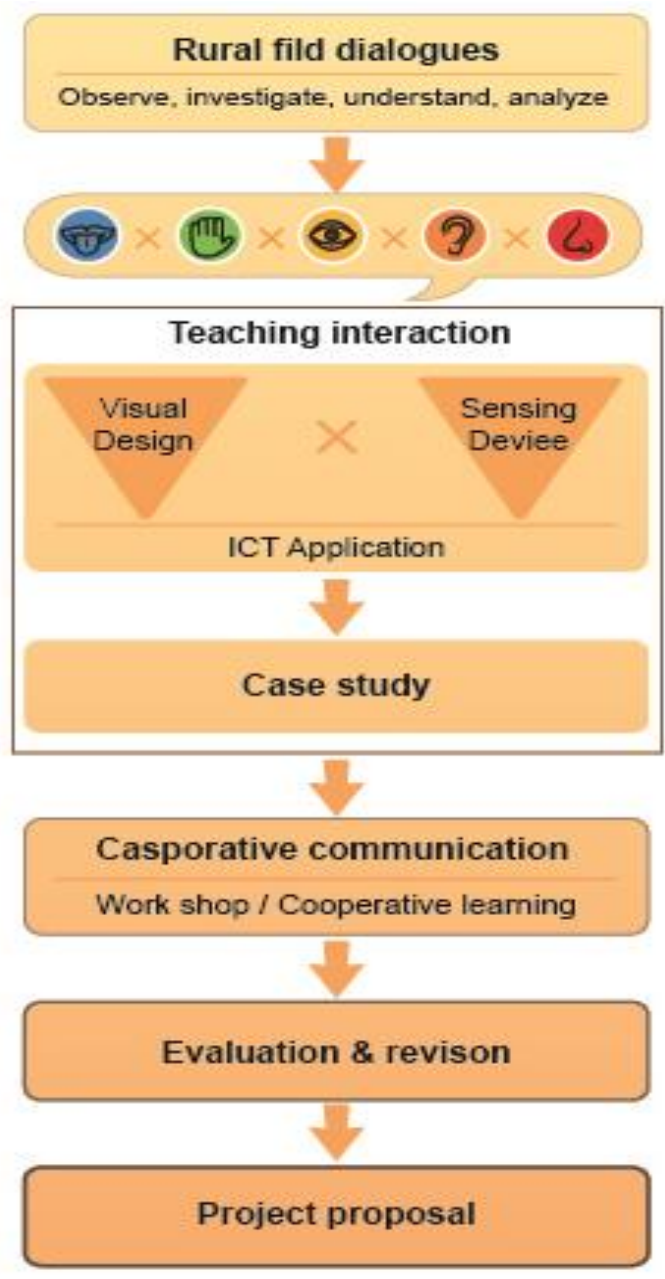

Fig. 8. Six stages of teaching interaction.

\section{ACKNOWLEDGMENT}

In acknowledgement of subsidy of the second-phase project of "Talent Cultivation Program for Smart Living Industry" of Ministry of Education and assistance of "Smart-A Union", this study succeeds in curriculum instruction and research analysis and allows students to experience interdisciplinary learning which expands their learning scope and vision.

\section{REFERENCES}

[1] Council of Agriculture, Executive Yuan. (2014). To promote the fine agricultural health excellence program. [Online]. Available: http://www.coa.gov.tw/htmlarea_file/web_articles/coa/11522/1-02.pd $\mathrm{f}$

[2] Ministry of Education. (2018). University social responsibility promotion center. [Online]. Available: http://usr.moe.gov.tw/.
[3] T. Kelley and J. Littman, "The ten faces of innovation: IDEO's strategies for beating the devil's advocate \& driving creativity throughout your organization,” New York: Currency/Doubleay, 2005.

[4] S. C. Kang, Cultivate Future Talents: T-Talent Workshop, Airiti Press Inc., 2017.

[5] R. M. Schafer, The Music of the Environment, Austria:Universal Edition, 1973.

[6] C. H. Wang, "The urban expression of the sound and scene-the environmental-sociological imagination of the twin cities," Journal of Building and Planning, no. 10, pp. 89-98, 2001.

[7] Design Council. (2007). Eleven lessons-managing design in eleven global brands: The design process. [Online]. Available: http://www.designcouncil.org.uk/sites/default/files/asset/document/El evenLessons_Design_Council (2).pdf

[8] Y. Tan, "Sensor development status and trends," Triple Enterprise Technology Industry Pulse Report, pp. 2-4, 2014.

[9] W. Y. Chiu, "Discuss the conservation of the "Shallow Mountain Ecosystem" from the 202th arsenal incident," Environmental Information Center, 2010

[10] P. F. Lee, "Report on the results of the investigation of shallow mountain ecological resources assessment and assessment committee," Construction and Planning Agency, MOI, 2016.

[11] Ministry of Education, "Transformation and breakthrough - Ministry of education talent cultivation white paper - Cultivating diversified talents, create a happy and prosperous society," Taipei: Ministry of Education Policy White Paper, 2013.

[12] Y. P. Zheng, "University education: Imagine: Stanford 2025's innovative university learning ecosystem," Journal of Education Research, vol. 266, pp. 96-112, 2016.

[13] D. W. Johnson and R. T. Johnson, "Learning together and alone: Cooperative, competitive, and individualistic learning," Prentice-Hall, Inc. 1987.

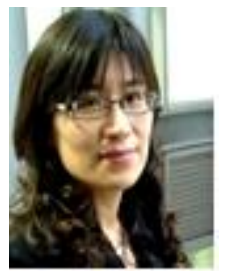

Li-Shu $\mathbf{L u}$ is an associate professor of digital media Design Department and Graduate School of Computational Design at the National Yunlin University of Science \& Technology (YunTech) in Touliu, Taiwan, R.O.C. Her research interest is design education; design method \& creative think; interactive Design; and usability in the interactive exhibition. In addition, in the context of soundscape is also very interested. Miss Lu served as designer in the design industry in July 1992 and June 1996, then, in 1997 transform in design education has been 20 years, and full of enthusiasm for teaching. Miss Lu has authored three books and authored, co-authored, or presented over forty-five articles, and conference presentations.

Associate Prof. Dr. Li-Shu Lu / Department of Digital Media Design \& Graduate School of Computational Design. 123 University Road, Section 3 , Douliou, Yunlin 64002, Taiwan (R.O.C.).

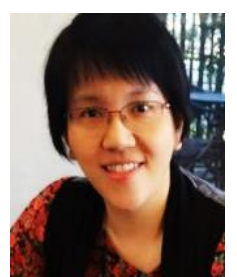

Pei-Fen Wu is an associate professor at the department of Information Management \& Master program in Digital Content Technology and Management, National Chunghua University of Education, Taiwan. She received her MFA in Multimedia and Animation Arts from National Taiwan University of arts in 2002, and a PhD in design from National Yunlin University of Science and Technology in 2010. For the past, she worked more than 14 years in multimedia design industry. She started teaching at school from 2009. Teacher Wu led the students to participate in the contest that number of awards exceeded 50. She also has won 6 outstanding teaching awards. She has published over 70 including journal and conference that use technology design to increase user' cognitive and affective. Her research interests include interactive media design, user-centered design, user experience, user interface, design thinking, digital story, user' cognitive, animation, technology-enhanced learning, and innovative design for the elderly.

Associate Prof. Pei-Fen Wu / Department of Information Management \& Master program in Digital Content Technology and Management, National Chunghua University of Education. 2, Shi-Da Road, Changhua City, Taiwan. pfwu@cc.ncue.edu.tw 